\title{
A validated method without derivatization for the determination of Letrozole by high performance liquid chromatography-fluorimetric method for pharmaceutical preparation
}

\author{
Cem Kaplan* (D), Durisehvar Ozer Unal(D) \\ Department of Analytical Chemistry, Faculty of Pharmacy, Istanbul University, 34116 Istanbul, Turkey
}

Cite this article as: Kaplan C, Özer Ünal D. A validated method without derivatization for the determination of Letrozole by high performance liquid chromatography-fluorimetric method for pharmaceutical preparation. Istanbul J Pharm 48 (2): 38 -42.

\begin{abstract}
A high performance liquid chromatography method has been developed for determination of letrozole in tablets. The method has developed in reverse phase column with acetonitrile- $50.0 \mathrm{mM}$ phosphoric acid solution, $\mathrm{pH}: 7$ (50:50, v/v) and 0.7 $\mathrm{mL} / \mathrm{min}$ flow rate by using a fluorimetric detector. Letrozole has natural fluorescence properties, and there is no need for derivatization for this molecule. The detector was set at 256, $585 \mathrm{~nm}$ for excitation and emission wavelength respectively. The method was validated in accuracy, precision, specificity, linearity and system suitability parameters are studied. The linear range was found $50-700 \mathrm{ng} / \mathrm{mL}$. The limit of detection and quantification for letrozole was found to be $14-50 \mathrm{ng} / \mathrm{mL}$ respectively. The recovery of drug is found to be $98.8 \%$. The developed method has been validated and successfully applied to tablet analysis of drug substance. This method is simple, reproducible and can be used safely for routine analysis of letrozole in tablets.
\end{abstract}

Keywords: Letrozole, HPLC-FLD, pharmaceutical preparation

\section{INTRODUCTION}

Letrozole, 4,4'-((1H-1,2,4-triazol-1-yl)methylene) dibenzonitrile is a nonsteroidal competitive inhibitor of the aromatase enzyme system; it inhibits the conversion of androgens to estrogens (Figure 1). Letrozole (LTZ) is used for the treatment of breast tumor which is estrogen-dependent. Breast cancer is also responsible for 18\% of deaths in cancer types (Lamb and Adkins, 1998; Annapurnaa et. al., 2012). In adult nontumor and tumor bearing female animals, letrozole is as good as ovariectomy in decreasing uterine weight, raising serum luteinizing hormone $(\mathrm{LH})$, and resulting in the regression of estrogen dependent tumors. Unlike ovariectomy, treatment with letrozole does not cause an increase in serum follicle stimulating hormone (FSH). Letrozole inhibits gonadal steroidogenesis but has no important effect on adrenal mineralocorticoid or glucocorticoid synthesis.

Letrozole inhibits the aromatase enzyme by binding to the heme of the subunit of the cytochrome P450 enzyme competitively, concluding in a decrease of estrogen biosynthesis in all tissues. women suffering from breast cancer with treatment of letrozole effect by reducing serum estrone, estradiol and estrone sulfate and hasn't been shown to importantly affect adrenal corticosteroid synthesis, aldosterone synthesis, or synthesis of thyroid hormones (Annapurnaa et. al., 2012; Scott and Keam, 2006).

Numerous drug substances of interest cannot be detected because the lack of the structural properties essential for the production of signals compatible with general detectors, such as ultraviolet (UV) absorbance and fluorescence. Derivatization can be used as an effective modification method that can improve the overall specificity and sensitivity of trace analyses. Besides these advantages, derivatization includes disadvantages such as lower yields and time-comsuming experimental procedures. Letrozole has natural flourencence properties to detect lower concentrations from various matrices.

In the literature, limited method can be found on letrozole analysis in pharmaceutical preparations. Mondal et al. developed a spectrophotometric technique for the determination of letrozole in pharmaceutical formulation (Mondal and Pal, 2009). The RP-HPLC method (Mondal and Pal, 2009; Pallavi et al., 2012) and spectrophotometric derivative method (Acharjya et al., 2010) 
Kaplan and Unal. A validated method without derivatization for the determination of Letrozole by high performance liquid chromatography-fluorimetric method for pharmaceutical preparation

have been reported for the analysis of letrozole from pharmaceuticals. Letrozole determination from biological materials were detected high performance liquid chromatography with fluorescence detector (HPLC-FLD) (Moussa et al., 2013; Rodrígez et al., 2013; Marfil et al., 1996; Zarghi et al., 2007) gas chromatography (Mareck et al., 2005), high performance liquid chromatography mass spectrometer (HPLC-MS) (Gomes and Bhosale 2013) and also stability studies of letrozole preparations were investigated (Mareck et al., 2005; Gomes and Bhosale 2013, Prasad and Govindrajulu, 2012). There is no publication of letrozole from pharmaceutical preparation by chromatographic method. The method developed can be applied to stability studies and also pharmacokinetic studies.

The aim of this study is to develop a simple and safe method based on fluorescence detection with a high performance liquid chromatography technique and an application of this method on pharmaceutical preparations.

\section{MATERIALS AND METHODS}

\section{Apparatus}

The HPLC system Shimadzu LC (liquid chromatography) 20 series (Shimadzu Analytical and Measuring Instruments, Kyoto, Japan) with fluorescence detector were used for the analysis of letrozole. The HPLC systems parts included a pump (Shimadzu

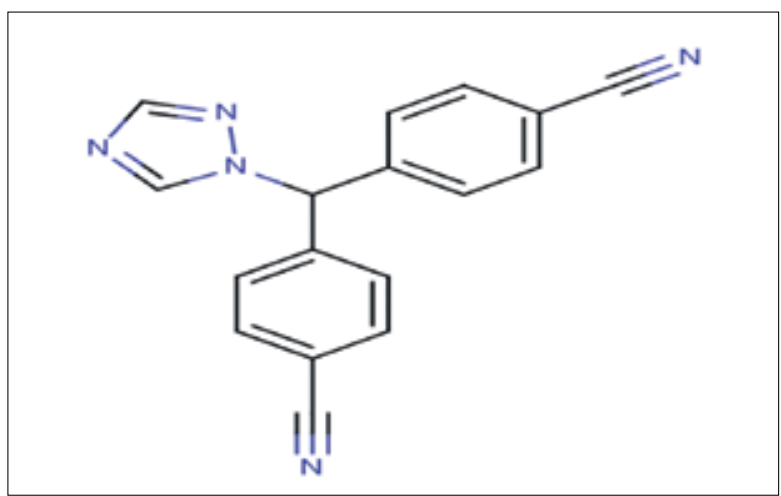

Figure 1. Structure of letrozole
LC-20AT) and an auto sampler (SIL-20HT). An instrument software (LC Solution) was also used.

\section{Chemicals}

All the chemicals were analytical grade. Letrozole was obtained from Natco Pharma Limited (India). Methanol which is HPLC grade was purchased from Sigma-Aldrich (Taufkirchen, Germany) and Acetonitrile which is HPLC grade was purchased from WWR (Vienna, Austria). HPLC grade solvents were also used. Femera" was used as a tablet which contains 2,5 mg LTZ.

\section{Chromatographic conditions}

Chromatographic separation was carried out at $25^{\circ} \mathrm{C}$ temperature using a reversed phase Intersil ODS (octadecyl silane) 5 um, 250x4.6 mm column (Tokyo, Japan). The mobile phase consists of acetonitrile: phosphate buffer $50 \mathrm{mM} \mathrm{pH:7} \mathrm{(50:50)}$ $(\mathrm{v} / \mathrm{v})$. The flow rate of the mobile phase was $0.7 \mathrm{~mL} / \mathrm{min}$. Letrozole has natural fluorescence properties and the detector was set at 256, $585 \mathrm{~nm}$ for excitation and emission wavelengths respectively. The injection volume chosen was $20 \mu \mathrm{L}$.

\section{Preparation of standard solutions and quality control samples}

A stock solution of LTZ (letrozole) $(0.1 \mathrm{mg} / \mathrm{mL})$ was prepared and diluted to LTZ2 $(1 \mu \mathrm{g} / \mathrm{mL})$ with methanol. All solutions were stored at $4^{\circ} \mathrm{C}$ until the end of the study. The five calibration standards were prepared with methanol between the concentration ranges of 50 and $700 \mathrm{ng} / \mathrm{mL}$. The quality control (QC) samples at a concentration of 50; 200; 400 and 700 ng/ $\mathrm{mL}$. All calibration standards and QC (quality control) samples were stored at $4^{\circ} \mathrm{C}$ until the end of the study.

\section{Analytical method validation}

In order to prove the acceptable nature of analytical method, the following protocol was performed during the method evaluation. There was no need for ethics committee approval for this study.

\section{RESULTS}

The chromatographic separation of analytes and other ingredients of drugs was optimized to provide an acceptable reso-

Table 1a. System suitability parameters of letrozole

\begin{tabular}{|lccccccc} 
Title & Retention Time & Area & Height & Concentration & k' & Tailing Factor & Theoritical Plate \\
\hline 0,05ltz_kal1_4.Icd & 9.991 & 189065 & 11477 & 0.050 & 2.223 & 1.120 & 7830.783 \\
0,1ltz_kal1_4.Icd & 9.989 & 428129 & 25201 & 0.100 & 2.222 & 1.134 & 7700.118 \\
0,3ltz_kal1_4.Icd & 9.980 & 1085090 & 63898 & 0.298 & 2.219 & 1.134 & 7760.786 \\
0,5ltz_kal1_4.Icd & 9.977 & 1783137 & 104200 & 0.499 & 2.218 & 1.133 & 7660.238 \\
0,7ltz_kal1_4.Icd & 9.970 & 2527196 & 148730 & 0.704 & 2.216 & 1.140 & 7752.800 \\
Average & 9.981 & 1202524 & 70701 & 0.330 & 2.220 & 1.132 & 7740.945 \\
\%RSD & 0.086 & 80.329 & 80.119 & 83.067 & 0.125 & 0.651 & 0.837 \\
Maximum & 9.991 & 2527196 & 148730 & 0.704 & 2.223 & 1.140 & 7830.783 \\
Minimum & 9.970 & 189065 & 11477 & 0.050 & 2.216 & 1.120 & 7660.238 \\
Standart deviation & 0.009 & 965977 & 56645 & 0.274 & 0.003 & 0.007 & 64.780 \\
\hline Itz: Letrozole & & & & & & & \\
kal: Calibration standards & & & & & & & \\
\%RSD: Relative standard deviation & & & & & & & \\
k: Capacity factor & & & & & & &
\end{tabular}


lution, a good peak shape and an intensity of the response. The mobile phase combination was changed consistently to establish chromatographic conditions giving an agreeable resolution. The retention time of letrozole is 9,9 minutes.

\section{System suitability test}

System suitability parameters summarized in Table 1a. were within acceptable limits. In Table 1b. system suitability accaptence limits are given according to FDA guidelines.

\section{Selectivity}

The selectivity of method was investigated by analyzing inactive ingredients of pharmaceutical preparations. Chromato-

\section{Table 1b. System suitability parameters in HPLC (According to FDA guideline)}

\begin{tabular}{|lc|}
\hline Parameter & Limit \\
\hline Capacity factor & $\mathrm{k}^{\prime}>2$ \\
Injection precision & $\mathrm{RSD}<\% 1, \mathrm{n} \geq 5$ \\
Resolution & $\mathrm{Rs}$ \\
Tailing factor & $\mathrm{T} \leq 2$ \\
Theoretical plate number & $\mathrm{N}>2000$ \\
\hline
\end{tabular}

grams were compared to the matrix for any interference or any of the method reagents ( Figure 2).

\section{Sensitivity}

The lowest standard of concentration $50 \mathrm{ng} / \mathrm{mL}$ for LTZ on the calibration curve was identified as the lower limit of quantification (LOQ) with a precision of less than or equal to $20 \%$. LOD ( limit of detection) was found $14 \mathrm{ng} / \mathrm{mL}$. The method developed is sensitive enough for the determination of LTZ from biological materials.

\section{Linearity}

The calibration curve contains five calibration samples within the range of $50-700 \mathrm{ng} / \mathrm{mL}$ including lower limit of quantification (LOQ) for LTZ. The acceptance criteria of back calculated concentration of standard batch was 15\% deviation from the nominal value excluding the LOQ (for LOQ, $20 \%$ deviation was applied). The standard calibration curves was linear over the concentration range from $700 \mathrm{ng} / \mathrm{mL}$ with a mean of $r^{2}=0.9998$ for LTZ. Accuracy and precision results of calibration standard can be shown in Table 2. The LOQ was $50 \mathrm{ng} / \mathrm{mL}$. The calibration curve had a regression equation of $\mathrm{y}=223827$ $\mathrm{X}+56.3597$.

Table 2. Accuracy and precision results of calibration standards

\begin{tabular}{|c|c|c|c|c|c|c|}
\hline Sample & Concentration $\mathrm{ng} / \mathrm{mL}$ & Mean & Recovered amount & Deviation(SD) & $\% \mathrm{CV}$ & $\mathrm{n}$ \\
\hline ST1 & 0,05 & 0,0496 & 99,2 & 0,002191 & 4,417117 & 6 \\
\hline ST2 & 0,1 & 0,099167 & 99,2 & 0,003251 & 3,277957 & 6 \\
\hline ST3 & 0,3 & 0,295167 & 98,4 & 0,006765 & 2,291962 & 6 \\
\hline ST4 & 0,5 & 0,497 & 99,4 & 0,011367 & 2,287046 & 6 \\
\hline ST5 & 0,7 & 0,689333 & 98,5 & 0,020363 & 2,954067 & 6 \\
\hline \multicolumn{7}{|c|}{$\begin{array}{l}\text { Accuracy is evaluated by mean and the recovered amount and precision is evaluated by standard deviation (SD) and coefficient of variation } \\
\text { (\%CV). } \\
\% \text { CV: Coefficient of variation } \\
\text { SD: Standard deviation } \\
\text { n: Number of samples }\end{array}$} \\
\hline
\end{tabular}
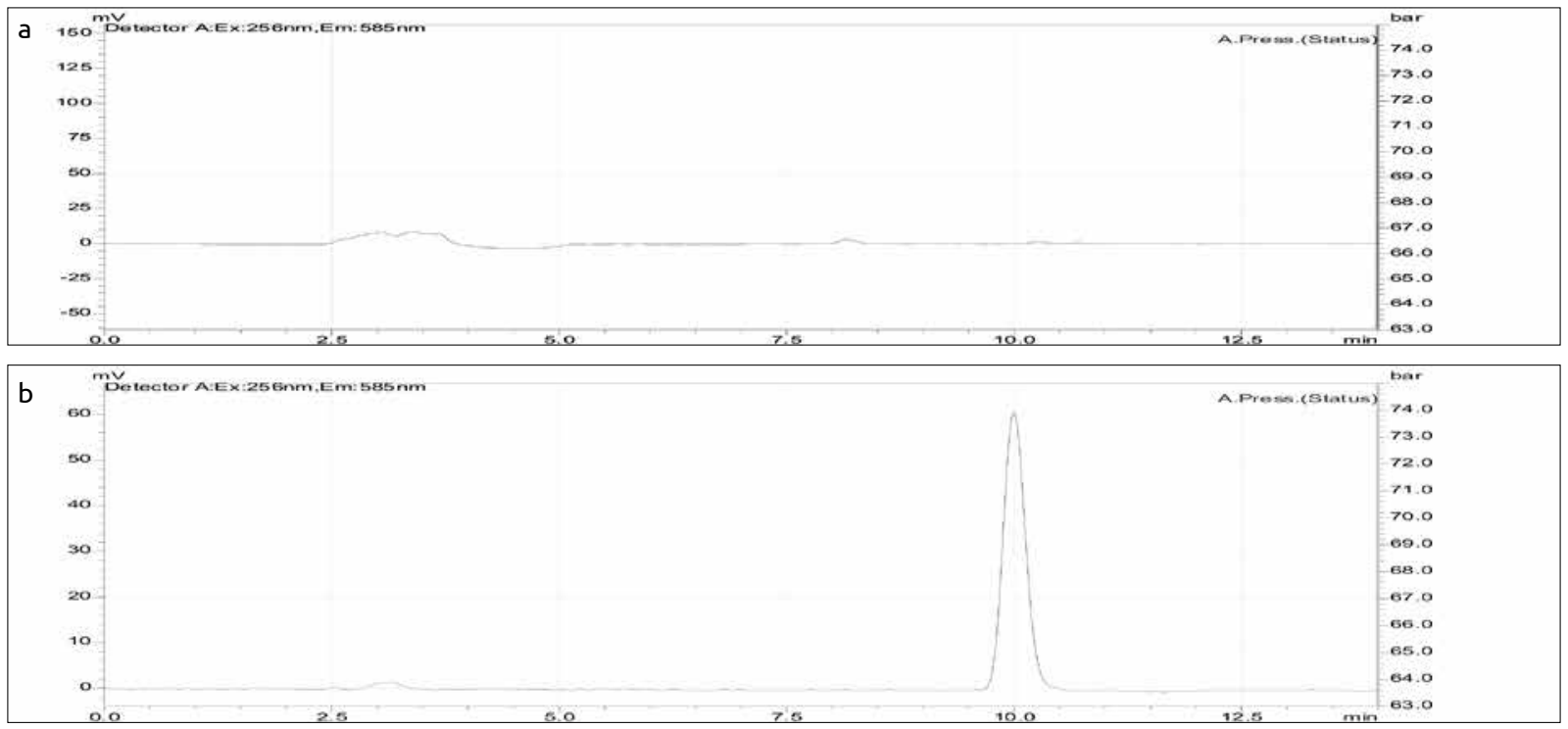

Figure 2. a, b. Placebo and letrozole ( $300 \mathrm{ng} / \mathrm{mL}$ ) Chromatogram 
Kaplan and Unal. A validated method without derivatization for the determination of Letrozole by high performance liquid chromatography-fluorimetric method for pharmaceutical preparation

Table 3. Results of accuracy and precision

\begin{tabular}{|lcccccc|}
\hline Sample & Concentration $\mathrm{ng} / \mathrm{mL}$ & Mean & Recovered amount & Deviation(SD) & \%CV & $\mathbf{n}$ \\
\hline QC1 & 50 & 0,048188 & 96.36 & 0,004665 & 9,680995 & 18 \\
QC2 & 200 & 0,195722 & 97.85 & 0,006676 & 3,410818 & 18 \\
QC3 & 400 & 0,402313 & 100.57 & 0,017843 & 4,435039 & 18 \\
QC4 & 700 & 0,689056 & 98.43 & 0,013584 & 1,9714 & 18 \\
\hline Accuracy is evaluated by mean and the recovered amount and precision is evaluated by standard deviation (SD) and coefficient of variation \\
$\begin{array}{l}\text { \%CV). } \\
\text { \%CV: Coefficient of variation }\end{array}$ \\
SD: Standart deviation \\
n: Number of samples
\end{tabular}

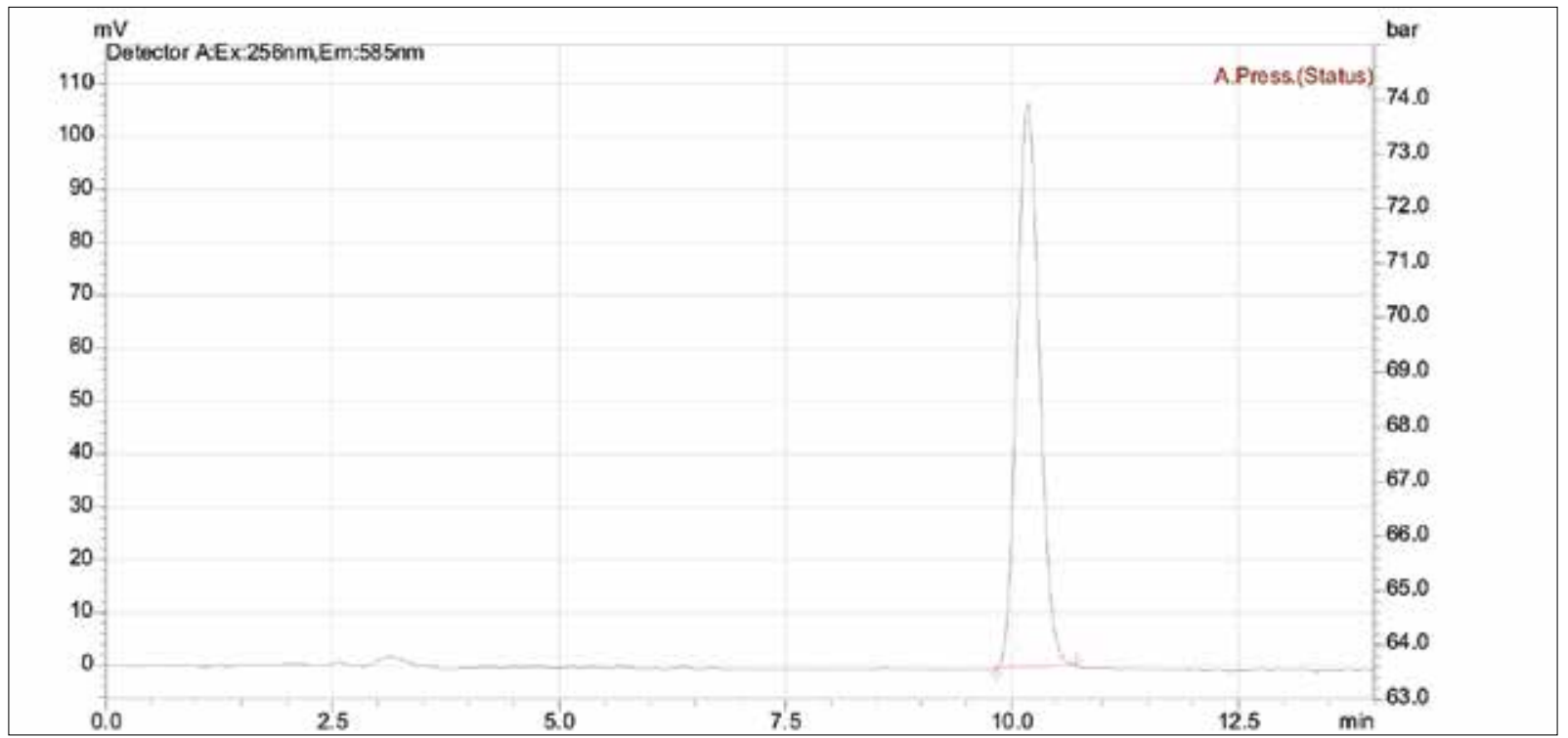

Figure 3. Chromatogram of $250 \mathrm{ng} / \mathrm{mL}$ tablet solution

\section{Accuracy and precision}

Precision and accuracy of intra-day were settled by analysis of six replicates of 5 concentrations including low, medium and high concentrations of quality control samples. Inter-day precision and accuracy were examined by the analysis of these quality control samples on three separate batches. The precision of the method was showed as the percentage of coefficient of variation and the accuracy of the method was showed in terms of relative errors. The precision was showed as the percentage of coefficient of variation. Table 3 presents a summary of the accuracy and precision.

\section{Sample preparation}

Tablet formulation containing $2.5 \mathrm{mg}$ LTZ, ten tablets were powdered and one tablet weight was diluted to $100 \mathrm{~mL}$ flask to volume with methanol, 6 replicates were prepared in this way. Further dilution was carried out by transferring an appropriate amount for $250 \mathrm{ng} / \mathrm{mL}$ final concentration (Figure 3). Recovery from pharmaceutical preparation was found to be $98.8 \%$.

\section{RESULTS AND DISCUSSION}

Letrozole has natural fluorescence properties which allows it to be analyzed without derivatization. System suitability parameters were within acceptable limits. The method developed has been validated. The method was found to be selective as seen in Figure 2. Chromatographic separation can differentiate the peak of analytes. The method was sensitive enough for the determination of letrozole from pharmaceutical preparations. Because of minority of papers on letrozole for pharmaceutical preparations, it is aimed to develop more sensitive and lower detection limits. Based on experiments and statistical analyses of letrozole, our data show that the proposed method demonstrates greater sensitivity to relevant studies including Mondal's (Mondal and Pal, 2009) and Narataj's (Nataraj et al. 2012). Considering the calibration curve and LOD and LOQ values, the proposed method is more sensitive than reported studies (Mondal and Pal, 2009; Pallavi et al., 2012). As a result, the correlation coefficient and the linear range of our method are more convenient and effective than the other studies Prasad et al. 2012), (Acharjya et al., 2010). This method can be applied to pharmaceutical analysis of letrozole for quality control during the process as well as cleaning swap analysis due to lower detection limit of the method. For further studies this method can be used for biological fluids such as plasma.

The developed method for the determination of LTZ from pharmaceutical preparation has been found accurate, precise, selective, and suitable for the quality control analysis. 


\section{Acknowledgements}

This study was supported by İstanbul University, Scientific Research Projects (ID:2020, Number: 48406).

Conflict of Interest: The authors have no conflict of interest to declare.

\section{REFERENCES}

- $\quad$ Acharjya S, Mallick P, Panda P, Kumar K, Annapurna M (2010) Spectrophoto $\neg$ metric methods for the determination of letrozole in bulk and pharmaceutical dosage forms. J Adv Pharm Technol Res 1(3): 348-353. [CrossRef]

- Annapurnaa M, Mohapatrob C, Narendrab A (2012). Stabilityindicating liquid chromatographic method for the determination of letrozole in pharmaceutical formulations. J Pharm Anal 2:298-305. [CrossRef]

- Gomes S, Bhosale S (2013). Application of sensitive rapid and validated liquid chromatography tandem mass spectrometry method for simultaneous determination of letrozole and metformin in hu $\neg$ man plasma. Int J Adv Res Pharm Bio Sci 3(2): 84-94.

- Lamb HM, Adkins JC (1998). Letrozole a review of its use in postmenopausal women with advanced breast cancer. Drugs $\mathbf{5 6}$ : 1125-1140. [CrossRef]

- Mareck U, Sigmund G, Opfermann G, Geyer H, Thevis M, Schän-zer W. (2005). Identification of the aromatase inhibitor letrozole in urine by gas chromatography/mass spectrometry. Rapid Commun Mass Spectrom 19(24): 3689-3693. [CrossRef]

- Marfil F, Pineau V, Sioufi A, Godbillon SJ (1996). Highperfor $\neg$ mance liquid chromatography of the aromatase inhibitor, le $\neg$ trozole, and its metabolite in biological fluids with automated liquid-solid extraction and fluorescence detection. J Chromatogr B Biomed Sci App/ 683: 251-258. [CrossRef]
- Mondal N, Pal TK (2009). Development and validation of RPHPLC method to determine letrozole in different pharmaceutical for $\neg$ mulations and its application to studies of drug release from nanoparticles. Acta Pol Pharm 66(1): 11-17.

Moussa B.A, El-Bagary R \& Osman E (2013). Determination of letrozole in pharmaceutical preparation and human plasma based on fluorometric detection. Anal Chem Lett 3: 139-146. [CrossRef]

- $\quad$ Nataraj K, Kumar D, Reddy S, Swamy B (2012). Stability indicating method devolopment and validation for related substances for letrozole tablets by RP-HPLC. Res J Pharm, Biol Chem Sci 4, 658-676 - Pallavi S, Vasanth PM, Ramesh T, Malothu R (2012). Devel-opment and validation of HPTLC method for the determination of letrozole in bulk and tablet dosage form. Int Res J Pharm 3: 202-204.

- Prasad H, Govindrajulu G (2012). Forced degradation study of letrozole a validated stability indicating HPLC assay for bulk and tablet dosage form. Int J Pharm Pharm Sci 4(2): 582-586.

- Prasad H, Govindrajulu G, Palaniyappan V (2012). Forced degradation study of letrozole-A vali-dated stability indicating HPLC assay for bulk and tablet dosage form. Int J Pharm Pharm Sci 4 , 582-586.

- Rodrígez J, Castañeda G, Muñoz L (2013). Rapid determination of letrozole, citalopram and their metabolites by high performance liquid chromatography-fluorescence detection in urine: Method validation and application to real samples. J Chromatogr B Biomed Sci App/ 913-914: 12-18. [CrossRef]

- Scott LJ, Keam SJ (2006). Letrozole: in postmenopausal hor $\neg$ mone-responsive early-stage breast cancer. Drugs 66: 35362. [CrossRef]

- Zarghi A, Foroutan S, Shafaati A, Khod $\neg$ dam A (2007). HPLC Determination of letrozole in plasma using fluorescence detection: Application to pharmacokinetic studies. Chromatographia 66(9) 747-750. [CrossRef] 